\title{
PUBLICIDADE COMPORTAMENTAL, PROTEÇÃO DE DADOS PESSOAIS E O DIREITO DO CONSUMIDOR
}

Fernando Inglez de Souza Machado* Regina Linden Ruaro**

RESUMO: O presente artigo busca enfrentar a questão da regulação da publicidade, enfocando na questão da proteção de dados pessoais. Diante do potencial econômico da publicidade, bem como da capacidade de esta influenciar na decisão dos consumidores, pretende-se verificar quais são os limites da prática publicitária, especialmente no que toca a utilização dos arquivos de consumo para fins de marketing direcionado. Para tanto, parte-se de uma construção histórica da publicidade e, com base no método dedutivo, enfrenta-se questões como a figura dos arquivos de consumo e a sua utilização e os limites à publicidade contextual a partir do direito do consumidor.

Palavras Chave: proteção de dados pessoais; direito do consumidor; publicidade comportamental; regulação da publicidade.

\section{BEHAVIOURAL ADVERTISING, PERSONAL DATA PROTECTION AND CONSUMER RIGHTS.}

ABSTRACT: The present article seeks to face the question of the regulation of publicity; focusing on the question of personal data protection. Facing the economic potential of publicity, as well as its capacity to influence on consumers decision, we intend to verify which are the limits of advertising, especially on the usage of consume files for direct marketing. Therefore, we start in a historical construction of publicity and, based on deductive method, we face problems as the figure of the consume files and its usage and the limits of contextual advertising based on the consumers rights.

Keywords: personal data protection; consumer rights; behavioral advertising; regulation of publicity;

\footnotetext{
* Mestrando em Direito no Programa de Pós-Graduação em Direito da Pontifícia Universidade Católica do Rio Grande do Sul - PPGD PUCRS. Bolsista Integral CNPq. Foi bolsista de iniciação científica, bolsa PIBIC, CNPq com projeto na área de Proteção de Dados Pessoais. E-mail: fernandoinglez@ hotmail.com

${ }^{* *}$ Professora Titular da Pontifícia Universidade Católica do Rio Grande do Sul - PUCRS. Doutora em Direito pela Universidad Complutense de Madrid (1993), com Pós-doutorado na Universidad de San Pablo-CEU de Madrid (2008). Compõe o Grupo Internacional de Pesquisa; Protección de datos, transparencia, seguridad y mercado. Email: ruaro@pucrs.br.
} 


\section{INTRODUÇÃO}

A figura da publicidade desempenha, hoje, papel fundamental na lógica do consumo. Mais do que veicular informações acerca de um determinado produto, a publicidade tem o condão de despertar o desejo pelo mesmo. Ela cria tendências, opiniões e até mesmo "necessidades" antes inexistes, de modo que a sua utilização influencia diretamente no mercado. Pode-se afirmar, com suficiente segurança, que a publicidade é pressuposto indispensável à atual lógica de consumo; publicidade e consumismo são dois fatores indissociáveis e extremamente presentes no cenário socioeconômico atual.

O potencial econômico da publicidade tem incitado a sua utilização abusiva e, por esta razão se torna relevante um controle jurídico capaz de proteger o consumidor. A ausência de regulação, por vezes, dá margem a práticas desleais, as quais atentam contra valores éticos e morais da sociedade, ou até mesmo contra a integridade do próprio público alvo, porque as condutas adotadas, em prol de uma maior influência publicitária sobre o consumidor, podem interferir na própria autonomia dele.

A diversificação dos meios de comunicação, em especial as novas mídias, dinamizaram as relações sociais e a própria noção de consumo. Não bastando a inserção do indivíduo em uma sociedade regrada pela lógica consumista, ele ainda é constantemente bombardeado por mensagens publicitárias no seu dia-a-dia, sendo compelido a alimentar o sistema, ou seja, a consumir cada vez mais.

Vale lembrar, ainda, que a publicidade já superou a dimensão puramente informacional, atingido um outro patamar - agora, ela atua sobretudo no psicológico do indivíduo, provocando desejos e vontades sobre ele. Não raramente, a fim de atingir tal objetivo, as empresas valem-se das informações que possuem a propósito do consumidor, para traçar seu perfil e, assim, determinar quais as preferências de cada indivíduo e quais deles têm maior prédisposição a desejarem determinado produto.

Tal aspecto ganha maior relevância quando nos deparamos com uma relação já marcada pela desigualdade. A vulnerabilidade do consumidor é intensificada pela lógica consumista, a qual é reforçada e impulsionada pela publicidade. Esta, por sua vez, tem, nos bancos de dados pessoais privados, uma ferramenta de grande utilidade, a qual se presta a tornar cada vez mais contundente a influência da publicidade sobre o consumidor. Frente a esta 
realidade, resta evidente a necessidade de estudos direcionados, a fim de verificar quais são os limites da publicidade mercadológica.

Cumpre enfatizar, a esse respeito, que a publicidade objeto do presente estudo consiste na publicidade de cunho comercial, ou seja, aquela voltada para o consumo. Diferentemente da publicidade (ideológica), cuja noção remonta ao surgimento do próprio homem e que não será enfrentada pelo presente, a publicidade comercial enfoca na questão do consumo e toma forma com o aparecimento dos meios de comunicação de massa, ou seja, da criação da imprensa (JACOBINA, 1996).

Tal publicidade é instrumento corriqueiro e de suma importância para a sobrevivência no mercado, atingindo todas as esferas sociais e, não raramente, de forma negativa. Então, é preciso entender como tal atividade funciona e quais valores são ameaçados pela sua prática de forma desregrada.

O presente artigo, por conseguinte, busca verificar os limites da atividade publicitária, especificamente no que concerne a problemática da utilização dos dados pessoais dos consumidores. Utilizando o método dedutivo, a presente pesquisa busca verificar até onde a publicidade - com especial enfoque na utilização de arquivos de consumo para fins de marketing direcionado - é legítima, ou seja, até que ponto ela não atenta contra os direitos de seu público alvo. Para tanto, traçar-se-á um panorama acerca da publicidade, partindo-se de uma construção histórica de tal ferramenta, para, então, confrontá-la com o direito fundamental a proteção de dados pessoais, depreendendo-se os limites jurídicos que tal direito enseja na prática publicitária.

\section{DO SURGIMENTO DA PUBLICIDADE COMERCIAL À SOCIEDADE DE CONSUMO}

A publicidade comercial, consoante se depreende do próprio nome, pressupõe uma relação de consumo. Não por acaso, é possível identificar uma correlação entre publicidade e imprensa. A revolução industrial resultou no fenômeno da produção em massa que, por sua vez, deu margem a criação da publicidade de massas. ${ }^{1}$ Até então, a publicidade era de cunho

\footnotetext{
${ }^{1}$ BENJAMIN (1994) afirmam que o primeiro anúncio (em inglês) de que se tem notícia data de 1477 anunciando livros de Willian Caxton, mas que foi no século XVII que os mais variados anúncios ganharam espaço na imprensa, in casu, nos jornais britânicos os mercuries.
} 
informativo, limitando-se a trazer informações pertinentes sobre o produto, de forma a permitir que o consumidor tivesse conhecimento acerca de sua existência e de suas qualidades.

O século XX, por sua vez, foi palco de um crescimento exponencial do fenômeno publicitário, notadamente pela multiplicação dos meios de comunicação, que deram margem a inúmeras possibilidades publicitárias. Contudo, foi somente na década de 1920 que a publicidade superou esse caráter fundamentalmente informativo, passando a ter contornos mais próximos ao seu estado atual, principalmente em razão do surgimento de novas mídias (era o caso do rádio e, posteriormente, da invenção da televisão) (BENJAMIN, 1994) e do desenvolvimento do marketing enquanto ciência. ${ }^{2}$

Surge, nesta década, a publicidade lastreada no lifestyle (estilo de vida), na qual a percepção do produto não se esgota em si mesmo. O produto agora é vinculado a uma noção de liberdade, paz, sucesso ou qualquer outro valor que se identifique como desejável no meio social. Dessa forma, a propriedade do produto acaba incutindo a obtenção desse valor, tornado o produto tão desejável quanto este. ${ }^{3}$

Esse American Way of Life dos anos $20^{4}$ deixou raízes na atual sociedade, em especial no que toca o mercado. A grande inovação desta sociedade tem, no marketing, um ator de destaque, vez que este foi o principal responsável pela transição de uma lógica em que a produção atendia a demanda, para uma lógica em que é a demanda que atende a produção. Em outras palavras, surge a chamada criação de demandas, figura que vai além da noção de necessidade (BAUMAN, 2013).

Há, então, uma cultura do consumismo, uma sobreposição do ter sobre o ser, impulsionada pelo bombardeio de publicidade, ao qual o indivíduo é diariamente submetido. ${ }^{5}$ Paulatinamente, foi-se inserindo a ideia de que é necessário consumir - não apenas bens essenciais, mas futilidades, desejos supérfluos - para se atingir a tão almejada felicidade. Em

\footnotetext{
${ }^{2}$ Ainda que persista a discussão de ser o marketing uma ciência ou uma arte, parece-nos que o "atual estado da arte" torna incontroversa a abordagem científica utilizada no desenvolvimento do próprio marketing e seus diversos campos de atuação. Atualmente, inclusive, já se fala até em Neuromarketing.

${ }^{3}$ Ricardo Ramos cria uma "fórmula Aida" da publicidade que pode ser dividida em quatro fases: atenção, interesse, desejo e ação. Na terceira fase - o desejo - mais que o desejo de compra, deve-se despertar o desejo de posse que é criado a partir do que o "ser humano tem de mais profundo - a ânsia de viver, a atração pelo sexo oposto, a ânsia de paz e segurança, a importância pessoal, o prazer..." (RAMOS apud. JACOBINA, 1996, p. 16-17)

${ }^{4} \mathrm{O}$ American Way of Life pode ser traduzido como estilo de vida americano. Trata-se de uma ideologia lastreada no enaltecimento dos direitos à vida, à liberdade e a busca da felicidade. Tal modo de pensar idolatrava o American Dream que consistia, dentre outras coisas, em ter os melhores e mais atuais bens de consumo como se isso fosse o caminho para a felicidade. Não por acaso, tanto o American Way of Life como o American Dream são amplamente atrelados à noção de consumismo.

${ }^{5}$ BEIJAMIN (1994, p. 5) aduz que a "publicidade é onipresente" estando em todos os meios de comunicação social e até de interação social (a exemplo das vias públicas ou dos esportes).
} 
suma, um fetiche coletivo foi-se firmando a partir dessa, de certa forma deturpada, consciência de consumo que fora imbricada na sociedade (BITTAR, 2002).

Percebe-se no fenômeno do consumismo uma confusão entre ser e ter. A vinculação de bens a estados de espírito, ou a conquistas pessoais acaba prejudicando o discernimento do consumido. Desvincular a pessoa em si de seus bens torna-se uma tarefa mais nebulosa, complexa e, portanto, ignorada pela maioria da população.

Não obstante, é inegável a importância da publicidade na sociedade contemporânea. A figura do marketing, em especial por meio da publicidade, foi indispensável à grande diversidade de produtos, serviços e facilidades de que dispomos hoje.

Ao impulsionar o mercado, atuando na formação do consentimento do consumidor, a publicidade deu margem a afirmação de que vivemos numa "economia de marketing", na qual é a produção que acompanha o marketing e não o contrário (BENJAMÍN, 1994).

Essa repentina "mudança de uma sociedade de escassez para uma de hiperconsumo formou um consumidor confuso, que recebe quantidade considerável de mensagens publicitárias não absorvidas" (SCHARF, 2012, p. 217). Assim, a publicidade, de tão ostensiva, acaba demandando uma nova lógica para sua readequação à sociedade consumista, seja pela criação de uma proposta de valor, ${ }^{6}$ seja por uma abordagem publicitária distinta. Em ambos os casos, contudo, pressupõe-se um requisito básico em comum: o acúmulo de informações e de conhecimento sobre o consumidor. ${ }^{7}$

\section{OS ARQUIVOS DE CONSUMO ENQUANTO FERRAMENTA DO MARKETING DIRECIONADO}

$\mathrm{Na}$ sociedade das novas tecnologias da informação e comunicação, os arquivos ou bancos de dados de consumo assumem uma importância fundamental para o êxito da publicidade. Cada vez mais, empresas criam seus cadastros de consumidores ou se associam a outras para troca de suas informações. Tal atividade é reconhecida no ordenamento jurídico brasileiro. No que concerne à matéria, o Código de Defesa do Consumidor (CDC) dispõe, em

\footnotetext{
${ }^{6}$ A proposta de valor é uma forma de criar uma identidade da marca, podendo ser "compreendida como a afirmação dos benefícios oferecidos pela marca ao cliente e que lhe proporcionam valor ... É entendida como uma estratégia eficaz ao conduzir a empresa a uma relação com o cliente, que o leva a decidir pela compra" (SHARF, 2012, p. 217.).

${ }^{7}$ A evolução tecnológica atual deu margem não só a existência de uma espécie de "Big Brother" idealizado por Orwell, mas das "littles sisters" de Huxley, traduzidas nas inúmeras empresas que coletam, tratam e cursam dados pessoais de seus clientes. (MENDES, 2014)
} 
seu artigo 43, caput, sobre os "cadastros, fichas, registros e dados pessoais e de consumo". Tais definições - bancos de dados e de cadastro - são empregadas para identificar os chamados arquivos de consumo, que seria o gênero que engloba aquelas espécies (MALHEIROS, 2007).

O marketing direcionado, por sua vez, atua basicamente sobre essa coleta de dados pessoais dos consumidores. Com base nessas informações, empresas de publicidade podem individualizar o consumidor a partir de seu perfil, direcionando apenas produtos compatíveis com aquele consumidor por meio de mensagens específicas. Ou seja, a mensagem publicitária passa a ter como destinatário um consumidor em específico, e não mais a população em geral (MENDES, 2014).

Surge, então, a publicidade contextual, ${ }^{8}$ enquanto ferramenta publicitária destinada a aumentar a eficiência das mensagens veiculadas ao preestabelecer um público alvo destinatário da mensagem. Quanto maior volume de informação que o fornecedor detiver sobre o consumidor, maior a eficiência da publicidade contextual e, nos padrões atuais de tratamento de dados pessoais, é alarmante o grau de conhecimento que as empresas possuem sobre os consumidores. ${ }^{9}$

É justamente tal ferramenta que possibilita a transição entre um modelo econômico de produção de massa para um lastreado na individualização e flexibilização em massa. Este modelo econômico "caracteriza-se pela oferta de volumes menores de produtos especializados, singularizados e altamente qualificados, em função do mercado e do consumidor" (MENDES, 2014, p. 86), contrastando com aquele modelo marcado pelo grande volume de produção de produtos padrão. Desta feita, o conhecimento sobre o consumidor permite que as empresas atendam as especificações individuais, numa espécie de customização do fornecimento de

\footnotetext{
8 "Uma forma quase instintiva para obter maior eficiência para esta mensagem publicitária é a sua veiculação em veículos de mídia dirigidos precisamente ao perfil do consumidor que teria maior interesse pelo produto ou serviço anunciado - esta é a chamada publicidade contextual, que busca a inserção da mensagem publicitária em um contexto no qual ela se harmonize com os interesses presumidos do consumidor.

Em paralelo a esta prática, o chamado marketing direto procura compilar, em bases de dados de consumidores, aqueles com maior potencial de compra para serem abordados diretamente. Tais bases de dados com informações pessoais sobre consumidores passaram a representar uma ferramenta valiosa e justificaram inclusive o nascimento dos primeiros programas de fidelização que, na década de 1980, começaram a ser oferecidos por fornecedores a seus consumidores mais frequentes e fiéis justamente para obter seu perfil mais acurado, em troca de eventuais vantagens e recompensas. "(DONEDA, 2010, p. 60-61)

${ }^{9}$ A penas a título de ilustração desse conhecimento acerca do indivíduo, remetemos o leitor a passagem do texto de Diogo CAMPOS (1996, p. 300): "O banco onde temos conta e a empresa que emitiu o nosso cartão de crédito, (sic.) estão em condições de reconstituir com bastante rigor a nossa vida, a nossa imagem. É, aliás, a eles que recorre a polícia quando pretende desmantelar uma quadrilha, detectar uma fuga aos impostos, invadindo nesse momento, todas as esferas da vida. E se o banco for solicitado a emprestar-nos uma quantia, tentará, através dos seus artigos informáticos, reconstituir a nossa imagem financeira. Assim, a nossa imagem, (sic.) está depositada em instâncias que, através dela, têm poder sobre nós."
} 
produtos e serviços, e, com o amparo pelos os mecanismos automatizados de tratamento de dados, a consequente customização pode ser feita em larga escala.

Percebe-se, neste cenário, a gritante assimetria informacional existente nas relações de consumo. Enquanto o consumidor tem acesso basicamente a informação disponibilizada pelo próprio fornecedor acerca de determinado produto e, eventualmente, a algum comentário de outro consumidor sobre este, o fornecedor capta dados do consumidor não só ao solicitar informações diretamente, mas a partir do dia-a-dia do indivíduo, a cada vez que ele acessa a internet ou que realiza alguma compra.

As informações contidas em bancos de dados de entes privados são fundamentais para o desenvolvimento de perfis de consumo, inclusive a ponto de se afirmar que "os dados pessoais constituem-se em condição sine qua non para essa nova configuração econômica" (MENDES, 2014, p. 84). Desta feita, tal situação deve ser considerada na intepretação da Seção VI do Capítulo V do Código de Defesa do Consumidor que não deve se restringir a cadastros para fins de proteção de crédito (por exemplo, SPC e SERASA).

Como se afirmou anteriormente, tem-se que da própria leitura do caput do artigo 44 do CDC, é possível identificar que os bancos de dados abordados na Seção VI, não se limitam à figura do consumidor, estendendo-se, também, à figura do fornecedor. ${ }^{10}$ Corroborando este entendimento, na oportunidade do julgamento do REsp 30.666-RS, o Ministro do STJ Dias Trindade já se manifestou no sentido de que o artigo 43 traz um rol exemplificativo de registros tutelados pelo $\mathrm{CDC}$ e que as regras contidas em tais artigos devem ser aplicadas de modo genérico. ${ }^{11}$

Posto isso, reitera-se que a perspectiva costumeira, ${ }^{12}$ elaborada a partir de uma leitura não extensiva do Código, que limita a aplicação das disposições previstas no CDC acerca de cadastros e bancos de dados apenas àqueles relativos a concessão de crédito não é suficiente. Faz-se necessária a interpretação extensiva, dessas disposições de modo que elas atinjam todos

\footnotetext{
10 Art. 44. Os órgãos públicos de defesa do consumidor manterão cadastros atualizados de reclamações fundamentadas contra fornecedores de produtos e serviços, devendo divulgá-lo pública e anualmente. A divulgação indicará se a reclamação foi atendida ou não pelo fornecedor.

${ }^{11}$ REsp 30.666/RS, Rel. Ministro DIAS TRINDADE, TERCEIRA TURMA, julgado em 08/02/1993, DJ 22/03/1993, p. 4544

${ }^{12}$ Nesse sentido, MALHEIROS (2007) entende que os primeiros bancos de dados e cadastros de consumidores surgem como ferramenta do mercado para socializar o custo do acúmulo de informações acerca dos consumidores e sua (in)adimplência do contrato, dando origem ao SPC e ao SERASA. Para o autor as informações concedidas servem para dar maior segurança às relações de consumo aumentando a segurança e a celeridade na concessão de crédito.
} 
os bancos de dados pessoais relativos a consumo, ainda que não relativos a concessão de crédito.

Nesse sentido, não é crível que a questão dos bancos de dados pessoais - a qual é extremamente sensível para a defesa do consumidor, especialmente ao se abordar a questão do marketing direcionado - seja ignorada no âmbito da relação de consumo. Forçoso lembrar, como bem aponta Doneda (2006), que o direito à proteção de dados pessoais não se presta apenas a proteção da privacidade do consumidor, estando atrelado, principalmente, às noções de autodeterminação, autonomia e de liberdade.

Os atuais incrementos tecnológicos no campo da informática permitem que as empresas utilizem os dados pessoais dos consumidores não só para fins de verificar a credibilidade do mesmo, mas para traçar verdadeiros perfis de consumo. Tal situação, somada a uma tendência à auto exposição dos indivíduos, ${ }^{13}$ empodera as empresas aumentando a desigualdade existente nas relações de consumo. ${ }^{14}$

As utilidades dessa manipulação de dados pessoais dos consumidores ultrapassam a própria figura do marketing direto. Atualmente, as grandes empresas traçam sua estratégia de mercado a partir da análise da renda, das preferências e do comportamento de seus clientes, determinando como e aonde alocarão seus recursos, utilizando tais informações desde para o desenvolvimento de produtos até à locação de pontos de venda (MENDES, 2014).

O processo de informatização permite uma nova forma de relação entre consumidor e fornecedor, todos os atos que aquele realiza alimentam as informações que este possui a seu respeito. Nenhuma conduta do consumidor é insignificante, elas repercutem em dados a seu respeito que, além de fugirem ao seu controle, são utilizados para finalidades diversas daquelas para as quais o ato foi praticado (DONEDA, 2010). ${ }^{15}$

Essa coleta de dados pode se dar tanto por meios diretos como indiretos. Os diretos consistem nos questionários e nos cadastros de consumidores, realizados no momento da obtenção de algum produto ou serviço, mediante sorteios, ou por meio de pesquisas de mercado

\footnotetext{
${ }^{13}$ Esta auto exposição pode ser atrelada tanto ao desenvolvimento tecnológico das novas mídias - como a criação de sites de relacionamentos a exemplo do Facebook - (CACHAPUZ, 2014) ou por uma necessidade de autoafirmação junto a sociedade de se fazer notar, fazendo o cogito de Descartes transformar-se em "sou visto (observado, notado, registrado), logo existo". (BAUMAN, 2013, p. 121).

${ }^{14}$ Deter informações sobre alguém concede poder sobre a pessoa de quem se tem informação (PODESTÁ, 2005), sendo que tal informação pode ser até mesmo sob a forma de imagem física, moral ou intelectual (CAMPOS, 1996).

${ }^{15}$ DONEDA (2010, p.61) trabalha a questão dos atos de consumo, os quais englobariam, inclusive, aqueles que antecedem a compra em si e servem como "compilação de abundante informação sobre o consumidor" que passa a ser tratado de forma individualizada.
} 
e de estilo de vida. Por outro lado, os meios indiretos são aqueles em que a obtenção de dados não é feita por arguição direta ao consumidor, dentre eles destacam-se a coleta de dados por meio de transações comerciais e cartões de fidelidade; de informações constantes em registros públicos e censos; e pelo uso da internet.

Nesse aspecto, é de suma importância destacar que existe uma substancial distinção entre as informações cedidas pelo consumidor diretamente e aquelas que são obtidas a partir do seu comportamento. Diferentemente das informações que são fornecidas pelo consumidor de forma voluntária (e consciente), as informações obtidas a partir de seu comportamento não passam por seu controle, fugindo a qualquer tipo de ponderação ou reflexão a seu respeito (DONEDA, 2010).

O acesso à internet é, hoje, uma das principais fontes de dados para a Publicidade Comportamental, ${ }^{16} \mathrm{em}$ especial a partir do online profiling (elaborações de perfis online). ${ }^{17} \mathrm{O}$ histórico de navegação, as buscas realizadas em ferramentas de pesquisa, as compras online, praticamente tudo é considerado na hora de destinar uma publicidade personalizada aos gostos e interesses do consumidor de forma quase pessoal.

Neste cenário, assusta o posicionamento do Tribunal de Justiça do Rio Grande do Sul (TJRS) firmado na Apelação Cível 70069420503 em Ação Coletiva ajuizada pelo Ministério Público contra o SERASA S.A. No julgado que ignora as construções doutrinárias acerca do direito à proteção de dados pessoais, o Tribunal consolidou o entendimento de que a venda de informações e de dados pessoais de consumidores sem a anuência destes não ofende direitos da personalidade do titular dos dados, desde que os dados não consistam em dados sensíveis, sigilosos ou confidenciais. ${ }^{18}$

\footnotetext{
16 "Online behavioral advertising involves the tracking of consumers' online activities in order to deliver tailored advertising. The practice, which is typically invisible to consumers, allows businesses to align their ads more closely to the inferred interests of their audience. In many cases, the information collected is not personally identifiable in the traditional sense - that is, the information does not include the consumer's name, physical address, or similar identifier that could be used to identify the consumer in the offline world. Instead, businesses generally use "cookies" to track consumers' activities and associate those activities with a particular 3 computer or device" (FTC Staff Report: Self-Regulatory Principles For Online Behavioral Advertising, 2009, p. 2)

${ }^{17}$ Online profiling ou network profiling é basicamente o principal instrumento de onile behavioral advertising operacionalizado por empresas de anúncios na internet (network advertising companies). Por meio dele se traça os interesses do usuário, com base em seus dados que são geralmente colhidos a partir de cookies e web bugs. Para maiores informações acerca desse assunto ver: Online Profiling: A Report To Congress, 2000. Disponível em: https://www.ftc.gov/system/files/documents/reports/online-profiling-federal-trade-commission-report-congressjune-2000/onlineprofilingreportjune2000.pdf

${ }^{18}$ Apelação cível. Responsabilidade civil. Ação coletiva. SPC BRASIL. Marketing service. Divulgação de dados. Ausência de ofensa a direitos da personalidade. Hipótese em que os dados divulgados não são sigilosos, pois se trata de informação fornecida nas relações negociais cotidianas. Inexistência de dados sensíveis. Apelos providos. (Apelação Cível N ${ }^{\circ} 70069420503$, Sexta Câmara Cível, Tribunal de Justiça do RS, Relator: Ney Wiedemann Neto, Julgado em 25/08/2016)
} 
A afirmação de Diogo Campos, ${ }^{19}$ lá em 1996, de que

Hoje, a cada momento, os cidadãos são pressionados para consumir e para destruir todos os obstáculos ao consumo (as crianças, os idosos, os pais, os não produtivos), para aceitarem ser organizados de modo a produzir mais e a consumir mais. Sujeitando-se a todos os constrangimentos, a todas as autoridades, a todos os modelos para poderem consumir. Qualificando de $<<$ sem sentido > as vidas dos que já não se podem organizar para trabalhar, rejeitando os desempregados, as mulheres-em-casa; etc. (CAMPOS, 1996, p. 298)

segue atual. Vivenciamos uma realidade em que o indivíduo é incessantemente incitado quando não coagido - a consumir e a superar qualquer obstáculo a esta atividade, inclusive submetendo-se a constrangimentos externos que viabilizem o consumo.

A esse respeito, de suma importância anotar que a formação de perfis não identifica apenas de forma positiva o consumidor, servindo também como forma de seleção de pessoas a partir de seu potencial de consumo. Uma das facetas do tratamento de dados pessoais dos consumidores é a sua utilização como mecanismo discriminatório ao selecionar apenas aqueles consumidores com um potencial de gerar lucro.

Como afirma Laura Mendes, a previsibilidade e a diminuição de riscos é uma das finalidades do tratamento de dados pessoais de consumidores. Nesse sentido, é possível identificar não só nos cadastros de proteção de crédito meios de discriminar consumidores, mas na própria seleção dos consumidores com base em seus próprios bancos de dados, excluindose aqueles que se enquadrem em uma categoria de risco e selecionando aqueles cujo potencial de gerar lucro seja satisfatório. Nas palavras da autora, "a consequência disso é a classificação das pessoas em categorias de acordo com a avaliação de seus riscos e a discriminação do acesso a determinados bens e serviços, de modo a afetar significativamente as suas chances de vida" (MENDES, 2014, p. 91).

O processo de identificação, classificação e análise de pessoas serve para identificar quais são as pessoas que merecem atenção do mercado e quais não. Ou seja, primeiro determinam quem você é (identificação), depois o que você é (classificação) e então verificam o seu valor econômico (análise). (GANDY Jr., 2011). ${ }^{20}$

\footnotetext{
19 "Hoje, a cada momento, os cidadãos são pressionados para consumir e para destruir todos os obstáculos ao consumo (as crianças, os idosos, os pais, os não produtivos), para aceitarem ser organizados de modo a produzir mais e a consumir mais. Sujeitando-se a todos os constrangimentos, a todas as autoridades, a todos os modelos para poderem consumir. Qualificando de $<<$ sem sentido $\gg$ as vidas dos que já não se podem organizar para trabalhar, rejeitando os desempregados, as mulheres-em-casa; etc." (CAMPOS, 1996, p. 298)

20"While developing actionable intelligence in support of strategic discrimination is the purpose for which these sophisticated analytics are brought into use (Gandy, 2009, pp. 19-34), this process ultimately depends upon the
} 
Tal situação pode se dar tanto no âmbito da publicidade em si, como na diferenciação das condições de acesso a produtos e serviços. No primeiro caso, pode-se identificar o fenômeno chamado de boxing. Este ocorre quando, a fim de se ajustar a publicidade ao perfil comportamental do consumidor, as empresas acabam limitando o rol de escolhas e, consequentemente, de acesso a mercadorias e serviços do consumidor. Tal questão torna-se problemática ao se pensar que essa limitação de escolhas ocorre com base no perfil atual traçado para o indivíduo, e que tal perfil não necessariamente o representará essa pessoa no futuro (DONEDA, 2010).

Quanto ao segundo caso, pode-se apontar o fato de que o mesmo serviço ou produto pode ser ofertado pelo mesmo fornecedor por valores ou condições de crédito distintos a duas pessoas, em razão de sua diferente classificação realizada pelo o fornecedor. Inclusive, os dados armazenados de um consumidor podem levar a uma negativa de acesso a determinados produtos, facilidades ou serviços com base no perfil que lhe foi traçado (DONEDA, 2010).

Em que pese o potencial lesivo desse tipo de atividade - que pode atingir a privacidade, a autonomia e a própria liberdade do indivíduo -, não se pode adotar uma posição radical a seu respeito. A elaboração de um perfil de um consumidor não é, por si só, algo necessariamente nocivo. Exemplo disso, Bauman (2013) aponta que seu perfil traçado pela Amazon lhe é de grande utilidade vez que filtra as opções de livros não só com base em suas compras, mas na de outros usuários com preferências potencialmente semelhantes as suas.

Em realidade, os bancos de dados, os perfis de consumo e os cadastros de consumidores dinamizam o mercado. Graças a esses arquivos de consumo é possível dar maior celeridade e segurança às relações de consumo, em especial aquelas que envolvem crédito. Outrossim, a personalização da publicidade - seja por publicidade comportamental ou contextual - pode servir tanto ao consumidor, que terá acesso a um conteúdo que lhe seja, provavelmente, mais útil e pertinente, como ao fornecedor que poderá empregar melhor seus recursos para fins de publicidade.

successful identification, classification, and evaluation of people, places and things as targets of interest (Wilkinson, 2008). Although it is convenient to distinguish between these different intermediate goals by suggesting that identification is about determining who you are, while classification is about determining what you are, there are additional distinctions to be drawn. The most important distinctions are those upon which economic valuations are made. All of these assessments act as aids to discrimination - guiding a choice between entities. Each choice represents an action that affects the status of entities as winners or losers in a game of chance (Dahrendorf, 1979). In many cases, the decisions made by the users of sophisticated analytics determine the provision, denial, enhancement, or restriction of the opportunities that citizens and consumers face both inside and outside formal markets."(GANDY Jr., 2011, p. 176) 
Destarte, cabe ponderar os limites desse tipo de prática do marketing direcionado. É preciso reconhecer a pertinência da utilização de dados pessoais como instrumento fundamental à atual lógica de mercado, sem que isso implique, contudo, na condescendência em relação a abusos e a violações aos direitos dos consumidores. Para tanto, passa-se a análise dos limites à publicidade comportamental e contextual.

\section{LIMITES À PUBLICIDADE COMPORTAMENTAL E À PUBLICIDADE CONTEXTUAL A PARTIR DO DIREITO DO CONSUMIDOR}

Seja por meio de uma autorregulação mais consistente, seja por meio da regulação estatal, é evidente a necessidade de que a publicidade tenha algum tipo de regulação. Não por acaso, até mesmo em países mais liberais como a França e os Estados Unidos da América a publicidade é objeto de regulação. No Brasil, tal construção não poderia ser diferente, ainda que se sustente que a publicidade esteja abrigada no direito fundamental à liberdade de expressão, ${ }^{21}$ nenhum direito, em que pese fundamental, é absoluto e, portanto, é passível de limitações para sua conformação com outros direitos fundamentais (SARLET, 2015).

O controle da publicidade serve para evitar abusos e danos ao consumidor em potencial, contudo isso não afasta o seu caráter lícito e até positivo - o estímulo do mercado quando norteado por princípios básicos. Nesse sentido, salvo em situações muito específicas, ${ }^{22}$ entende-se que a solução mais adequada é a de contenção e não supressão da publicidade (BENJAMÍN, 2006).

Inicialmente, o Brasil adotava o sistema de auto-regulamentação publicitária, que, em razão da ausência de vinculatividade dos pareceres do CONAR e da ausência de poder coercitivo do Conselho, cuja competência limita-se a imposição de pena de caráter meramente simbólico, mostrou-se insuficiente para evitar abusos (ROCHA, 2012). Com isso, o País passou

\footnotetext{
${ }^{21}$ No Brasil existe grande discussão no âmbito doutrinário quanto à inserção da publicidade no âmbito do direito fundamental à liberdade de expressão ou no âmbito do direito à liberdade comercial, porém tal questão não será enfrentada no âmbito deste artigo, uma vez que foge do objeto estudado.

${ }^{22}$ Existem alguns produtos sobre os quais a propaganda é vedada, a exemplo do fumo - art. $3^{\circ}$ da Lei n. 9.294.
} 
a adotar o modelo misto, ao menos teoricamente, ${ }^{23}$ para fins de regulamentação da publicidade. $^{24}$

O controle autorregulamentar da publicidade se dá principalmente pela atuação do CONAR (Conselho Nacional de Autorregulamentação Publicitária) criado no final da década de 1970 como uma iniciativa para evitar que o governo regulasse a publicidade (DIAS, 2010). Trata-se de sociedade civil sem fins lucrativos, cuja incumbência é a de fiscalizar a propaganda no Brasil com base no Código Brasileiro de Autorregulamentação Publicitária - texto que serve inclusive como subsídio no âmbito jurídico, ainda que suas normas não possuam caráter jurídico (DIAS, 2010).

O aludido código estabelece, em seu Capítulo II, princípios gerais para a publicidade, dentre eles destacam-se: a respeitabilidade; a decência; a honestidade; a vedação ao apelo ao medo, à superstição ou à violência; a apresentação verdadeira; a identificação publicitária; limites à propaganda comparativa; a segurança; a proteção da intimidade; a proteção ecológica; a proteção de crianças e jovens; e a proteção dos direitos autorais. ${ }^{25}$

Quanto à regulação Estatal, cumpre referir que o argumento de que a publicidade é constitucionalmente protegida ao se enquadrar como liberdade de expressão - art. 5, IX da CF - e, portanto, não é passível de limitação por parte do Estado é extremamente precário. Primeiro, a própria questão do enquadramento da publicidade como exercício da liberdade de expressão não é pacífica. ${ }^{26}$ Segundo, ainda que se entenda que a publicidade esteja sob a proteção da liberdade de expressão, tal situação não afasta a sua limitação, vez que nenhum

\footnotetext{
${ }^{23} \mathrm{Na}$ prática, percebe-se que a atuação do CONAR continua deficitária e até mesmo irrelevante, vez que persiste o caráter não obrigatório e não coercitivo de suas decisões (PASQUALOTTO, CAUDURO, 2016). Apenas no que concerne o Código Brasileiro de Autorregulamentação Publicitária é que se extrai maior influência do CONAR na regulamentação da publicidade, vez que este serve de suporte à legislação e ao próprio Judiciário.

${ }^{24}$ Existem três modelos de regulação da publicidade: a auto-regulamentação pura, de caráter privado, baseada na autovinculação; a regulação estatal pura, na qual cabe ao Estado tutelar os interesses dos destinatários da publicidade diante de eventuais abusos; e o modelo misto, que parte do "pressuposto que a auto-regulamentação não exerce sobre os seus regulados uma autoridade suficiente ao ponto de tornar desnecessária a intervenção estatal, e que esta, ao ser aplicada isoladamente, apresenta igualmente riscos para o consumidor." (BENJAMÍN, 2006, p. 39)

25 Código Brasileiro de Autorregulamentação Publicitária. Disponível em: http://www.conar.org.br/codigo/codigo.php. Acesso em: 04 abr. 2016.

${ }^{26}$ Em que pese a pertinência da discussão, ela não será objeto de análise no pressente estudo por demandar uma abordagem mais específica, a qual foge do objeto em análise. Destarte, insta referir, apenas, que, apesar de nãos configurar corrente majoritária, diversos autores entendem que a publicidade não está sob o abrigo da proteção da liberdade de expressão devido ao seu caráter notadamente comercial, voltado a práticas de consumo e não a divulgação de ideias ou opiniões (ou seja, manifestações de cunho político ou de expressão de cidadania), dentre eles Adalberto Pasqualotto, Raquel Heck da Rocha, Paulo Jacobina e Antônio Vasconcellos e Benjamín.
} 
direito é absoluto, sendo exagerada a intangibilidade almejada para tal garantia constitucional (ROCHA, 2012).

O controle legal da publicidade não implica em censura, servindo como freio a eventuais abusos frente ao consumidor (BENJAMÍN, 1994), e foi somente a partir da promulgação do Código de Defesa do Consumidor que a matéria foi abordada sob a perspectiva deste. O referido diploma legal traz uma seção específica à questão da publicidade, inserida no capítulo destinado às práticas comerciais (capítulo V), ensejando tanto uma tutela difusa como individual frente a publicidade.

Da leitura da seção III do Código, destinada à publicidade, depreende-se os princípios: da identificação (art. 36, caput); da transparência da fundamentação ou do embasamento (art. 36, parágrafo único); da veracidade e da informação ( $\operatorname{art.} 37, \S 1^{\circ}$ e $\S 3^{\circ}$ ); da não abusividade (art. 37, §2º ; e da inversão do ônus da prova (art. 38).

A partir do princípio da identificação, configura-se ilícita toda a publicidade oculta, que consiste tanto na publicidade disfarçada como uma reportagem ou outra forma de relato imparcial, como na publicidade subliminar. O princípio da transparência da fundamentação, por sua vez, dá ensejo até mesmo a responsabilização penal - art. 69, CDC - não só é preciso manter os dados que embasam a publicidade, mas eles devem estar à disposição daqueles legitimamente interessados (vide art. 82, CDC).

A questão da veracidade e da informação contrapõem-se a chamada publicidade enganosa. Esta consiste, nos termos do $\$ 1^{\circ}$ do art. 37 do CDC, em "qualquer modalidade de informação ou comunicação de caráter publicitário, inteira ou parcialmente falsa, ou, por qualquer outro modo, mesmo por omissão, capaz de induzir em erro o consumidor a respeito da natureza, características, qualidade, quantidade, propriedades, origem, preço e quaisquer outros dados sobre produtos e serviços", sendo que a publicidade enganosa por omissão, configurar-se-ia quando a mensagem deixasse de comunicar dado essencial do produto ou serviço. Ou seja, a publicidade enganosa não pressupõe, necessariamente, a existência de informação falsa, bastando a indução do consumidor ao erro, seja pelo contexto em que a informação é veiculada, seja pela omissão de algum dado relevante (DIAS, 2010).

De suma relevância referir, também, que, a exemplo dos tribunais norte-americanos, o Direito brasileiro considera, para fins da ilicitude por propaganda enganosa, não apenas o "homem médio", mas todos aqueles que são expostos a propaganda, como a criança e pessoa 
desprovida de educação. Assim, “o que se exige, para a caracterização do ilícito civil, é a potencial capacidade para enganar, ainda que uma minoria significante de consumidores" (JACOBINA, 1996, p. 92).

Parece-nos, assim, que um controle, a priori, de uma publicidade potencialmente enganosa deve levar em consideração o público alvo da mensagem publicitária. Porém, em se tratando de comprovado prejuízo do consumidor, é preciso levar em consideração as especificidades inerentes ao consumidor lesado.

A tutela contra a abusividade decorre não só do Código de Defesa do Consumidor, como de prescrição constitucional. ${ }^{27} \mathrm{O} \$ 2^{\circ}$ do art. 37 do $\mathrm{CDC}$ define como abusiva "a publicidade discriminatória de qualquer natureza, a que incite à violência, explore o medo ou a superstição, se aproveite da deficiência de julgamento e experiência da criança, desrespeita valores ambientais, ou que seja capaz de induzir o consumidor a se comportar de forma prejudicial ou perigosa à sua saúde ou segurança”. Tal rol é, apenas, exemplificativo, consoante se depreende da expressão “dentre outras” constante no início do referido parágrafo.

A intepretação da figura da publicidade abusiva pode ser feita com base no instituto do abuso de direito a partir do qual ela foi inspirada. Considera-se ato abusivo todo aquele que vai de encontro aos valores, aos princípios, aos bons costumes e à "finalidade econômica e social do direito", admitindo-se, inclusive, a sua modalidade objetiva - ou seja, aquela que independente de dolo ou de culpa. (DIAS, 2010, p. 161).

Destarte, ao se falar publicidade abusiva, busca-se tutelar, na figura do consumidor, valores inerentes ao ordenamento jurídico como um todo, em especial os previstos na Constituição Federal. Assim, é abusiva toda prática publicitária que atente contra a dignidade da pessoa humana, a não discriminação, a proteção da criança e do adolescente, à intimidade e à vida privada, dentre outros (DIAS, 2010).

No caso específico da publicidade contextual e comportamental, a questão regulatória centra-se principalmente em aspectos como o livre consentimento do consumidor, a proteção da privacidade, a transparência da atividade publicitária e a possibilidade de recusa (DONEDA,

\footnotetext{
${ }^{27}$ Art. 220. A manifestação do pensamento, a criação, a expressão e a informação, sob qualquer forma, processo ou veículo não sofrerão qualquer restrição, observado o disposto nesta Constituição. II - estabelecer os meios legais que garantam à pessoa e à família a possibilidade de se defenderem de programas ou programações de rádio e televisão que contrariem o disposto no art. 221, bem como da propaganda de produtos, práticas e serviços que possam ser nocivos à saúde e ao meio ambiente.
} 
2010). A limitação à publicidade, consoante se percebe, não se limita ao conteúdo de sua mensagem. Consoante aponta Jacobina (1996, p. 95), “a publicidade não é só conteúdo ... Ela é, principalmente, forma".

A questão do livre consentimento do consumidor desdobra-se numa relação de dependência com o princípio da identificação. Para se obter um livre consentimento é preciso, primeiramente, que o consumidor possa identificar, de pronto, que está diante de uma mensagem publicitária.

Outro requisito imprescindível ao livre consentimento atrela-se ao princípio da informação, tratando-se da transparência da atividade publicitária. A fim de que o consumidor possa ponderar acerca da conveniência e pertinência da publicidade, a ponto de consentir com a mesma, é preciso informá-lo ao menos quais dos seus dados serão objeto de coleta e de tratamento, bem como quem terá acesso a eles (DONEDA, 2006, 2010).

A possibilidade de recusa seria algo posterior ao consentimento, aspecto trabalhado sob o nome de ongoing consent, em razão do caráter contínuo da publicidade comportamental. Nesse sentido, "não só a possibilidade de revogação do consentimento deve estar sempre presente, como esta possibilidade deve ser disponibilizada de forma ostensiva e mesmo facilitada" (DONEDA, 2010, p. 97).

No caso da privacidade, por fim, é notória a ausência de regras capazes de compor uma tutela efetiva no âmbito da publicidade, ${ }^{28}$ em especial por causa do acúmulo de informações a partir do comportamento do consumidor. Como resposta, surgem mecanismos como o do not track - ferramenta de navegadores da internet em que se manda uma solicitação de não rastreamento da navegação do usuário quando se acessa algum site -, ou a criptografia - ferramenta que pode ser utilizada tanto para codificar mensagens, restringindo o acesso ao seu conteúdo, como para certificar a autoria da mensagem ou a integridade de seu conteúdo.

Tais mecanismos são exemplos das Privacy Enhancing Tecnologies (PETs), que são desenvolvidas para dar maior segurança ao usuário. Dentre elas cabe destacar, ainda, a P3P -

\footnotetext{
${ }^{28}$ Têm-se apenas, no Código de Defesa do Consumidor, a garantia de acesso as informações pessoais - art. 43, caput -; a vedação à manutenção de informação negativa por prazo superior a cinco anos - art. $43, \S 1^{\circ}$-; o dever de comunicação ao consumidor - art. $43, \S 2^{\circ}$-; e a possiblidade de correção dos dados - art. 43, $\$ 3$. Para além deste, a tutela da privacidade é esparsa no ordenamento jurídico, havendo previsão constitucional de sua proteção, bem como em outros textos infraconstitucionais. Não obstante, ainda carecemos de uma regulação específica da proteção de dados pessoais dando margem a práticas cujo potencial lesivo é significante.
} 
Plataform for Privacy Preferences que funciona como uma espécie de configuração prévia do usuário sobre quais dados ele consente a coleta e qual a forma de sua utilização. Conforme o usuário navega pela internet essa ferramenta compara as políticas de dados entre o sítio da internet e as configurações estabelecidas pelo usuário, emitindo um alerta a este quando houver excessos por parte do provedor do conteúdo no que toca a política de dados pré-configurada pelo usuário (BELLEIL apud MENDES, 2014).

Ainda que de notável relevância a criação e o fomento da utilização dessas tecnologias de proteção à privacidade, elas não são suficientes para uma efetiva tutela da privacidade no âmbito da publicidade e do marketing direcionado. É latente a necessidade de sua atuação amparada por outros "instrumentos de política pública aptos a realizarem a proteção da privacidade, como lei e regulamentos estatais, bem como instrumentos de autorregulação" (MENDES, 2014, p. 107). Somente a partir de uma atuação específica sobre a proteção dos dados pessoais é possível tutelar a privacidade do consumidor diante dos incrementos tecnológicos que remodelam a nossa sociedade.

\section{CONCLUSÃO}

Do exposto, verifica-se que a publicidade é imprescindível à estrutura do mercado atual. A figura do marketing, em especial por meio da publicidade, é responsável pela dinamização da relação de consumo, tendo como consequência a existência dessa infinidade de produtos, serviços e facilidades dos quais dispomos hoje. Ao atuar diretamente na formação do consentimento do consumidor, a publicidade impulsiona a economia e o desenvolvimento tecnológico.

Não obstante, é preciso ter em vista o potencial lesivo de tal prática. A assimetria existente na relação de consumo se intensifica quando a publicidade ultrapassa um caráter meramente informativo e atinge um patamar de influenciar a conduta dos indivíduos. Tal situação, quando contextualizada numa sociedade de informação em que os dados pessoais dos consumidores servem como verdadeiro insumo de produção, torna o problema ainda mais sensível.

A partir do momento em que as empresas passam a utilizar informações do consumidor para individualiza-lo e, posteriormente, classifica-lo, há uma ruptura do equilíbrio entre as partes - consumidor e fornecedor de produtos ou serviços. A publicidade comportamental 
surge, nesse aspecto, como ferramenta que dá maior eficiência à comunicação mercadológica da empresa, vez que atua sobre pessoas conhecidas, ou seja, sobre pessoas das quais se sabe o comportamento, as preferências, a capacidade financeira, dentre outros aspectos de sua vida.

Nesse sentido, percebe-se a necessidade da identificação de limites da publicidade em geral e, especificamente no que toca o objeto do presente estudo, da publicidade comportamental e contextual. A regulação existente no Código de Direito do Consumidor demonstra sua relevância ao coibir determinadas práticas que atentam contra a pessoa do consumidor, prevendo princípios a serem observados na prática publicitária.

No mesmo sentido, o CONAR também traz, a partir do Código Brasileiro de Autorregulação publicitária, diversas limitações a essa prática, porém não sendo dotado de nenhum efeito coercitivo efetivo. Tal situação, como já referido, põe em xeque a alegação da implementação de um regime misto de regulação da publicidade no âmbito brasileiro, que acaba recaindo basicamente ao controle Estatal.

Quanto à publicidade comportamental em si, a problemática recai especialmente sobre a questão do tratamento de dados pessoais. Os mecanismos utilizados para a implementação dessa espécie de publicidade são verdadeiras ameaças aos direitos à igualdade, à privacidade, à personalidade e à proteção de dados pessoais. Mecanismos como online profiling e online behavior advertising demonstram a vulnerabilidade do consumidor frente a essas práticas típicas do mercado atual.

A ausência de controle do indivíduo sobre suas próprias informações o deixa desamparado frente ao ímpeto esmagador das grandes empresas em compeli-lo ao consumo, por meio de técnicas que atuam sobre o seu psicológico. Destarte, é forçoso reconhecer a importância de tecnologias de proteção à privacidade, que devem ser amparadas por políticas públicas sérias, que regulem de forma mais específica a publicidade e, especialmente, a proteção dos dados pessoais, bem como viabilizem uma conscientização e um empodeiramento do consumidor.

\section{REFERÊNCIAS}

BAUMAN, Zygmunt. Vigilância Líquida: Diálogos com David Lyon. Tradução Carlos Alberto Medeiros. Rio de Janeiro: Zahar, 2013. 
BENJAMIN, Antônio Herman de Vasconcellos e. O controle jurídico da publicidade. Revista de Direito do Consumidor, n. 9, p. 25-57, jan./mar. 1994. Disponível em:

<http://bdjur.stj.jus.br//dspace/handle/2011/8981>. Acesso em: 31 mar. 2016

\section{BITTAR, Eduardo C. B. Contribuições Para a Crítica da Consciência Consumista e Acerca} da Construção dos Direitos do Consumidor. In: BITTAR, Eduardo C. B. e CHINLATO, Silmara Juny. (coord.). Estudos de direito de autor, direito da personalidade, direito do consumidor e danos morais: homenagem ao professor Carlos Alberto Bittar. Rio de Janeiro: Forense Universitária, 2002.

BRASIL. Código Brasileiro de Autorregulamentação Publicitária. Disponível em: <http://www.conar.org.br/codigo/codigo.php.>. Acesso em: 04 abr. 2016.

CAMPOS, Diogo Leite de. A imagem que dá Poder: Privacidade e Informática Jurídica. Comunicação e defesa do consumidor. Actas do Congresso Internacional organizado pelo Instituto Jurídico da Comunicação da Faculdade de Direito da Universidade de Coimbra. Coimbra, 1996.

CACHAPUZ, Maria Cláudia. Intimidade e vida privada no novo Código Civil brasileiro: uma leitura orientada no discurso jurídico. Porto Alegre: Fabris Editora, 2006.

DIAS, Lucia Ancona Lopez de Magalhães. Critérios para a avaliação da ilicitude na publicidade. Tese de doutorado. Faculdade de Direito da USP, 2010.

DONEDA, Danilo. A proteção de dados pessoais nas relações de consumo: para além da informação creditícia. Brasil, Escola Nacional de Defesa do Consumidor. Brasília:

SDE/DPDC, 2010. Disponível em:

<http://www.vidaedinheiro.gov.br/docs/Caderno_ProtecaoDadosPessoais.pdf>. Acesso em: 01 abr. 2016.

DONEDA, Danilo. Da privacidade à proteção de dados pessoais. Rio de Janeiro: Renovar, 2006.

FTC Staff Report: Self-Regulatory Principles For Online Behavioral Advertising. 2009. Disponível em: <https://www.ftc.gov/sites/default/files/documents/reports/federal-tradecommission-staff-report-self-regulatory-principles-online-behavioraladvertising/p085400behavadreport.pdf>. Acesso em: 04 abr. 2016. 
GANDY Jr., Oscar H. Consumer Protection in Cyberspace. in: $C C$ : Creative Commons License, v.9, n. 2, 2011. Disponível em:

<http://triplec.at/index.php/tripleC/article/viewFile/267/241>. Acesso em: 29 mar. 2016.

JACOBINA, Paulo Vasconcelos. A publicidade no direito do consumidor. Rio de Janeiro: Forense, 1996.

MALHEIROS, José Eduardo. Banco de dados e cadastro de consumidores - artigos 43/45. Dissertação de Mestrado. Pontifícia Universidade Católica de São Paulo, 2007.

MENDES, Laura Schertel. Série IDP - Linha de pesquisa acadêmica - Privacidade, proteção de dados e defesa do consumidor: linhas gerais de um novo direito fundamental, $1^{a} \mathrm{Ed}$. Saraiva. VitalSource Bookshelf Online.2014.

Online Profiling: A Report To Congress, 2000. Disponível em: $<$ https://www.ftc.gov/system/files/documents/reports/online-profiling-federal-tradecommission-report-congress-june-2000/onlineprofilingreportjune2000.pdf>. Acesso em: 04 abr. 2016.

PASQUALOTTO, Adalberto de Souza. CAUDURO, Luiza Kremer. Sistemas de autorregulamentação da publicidade: um quadro comparativo entre países. Revista da Faculdade de Direito da UFRGS. Porto Alegre, n. 35, p. 207-230, vol. esp., dez. 2016. PODESTÁ, Fábio Henrique. Direito à intimidade em ambiente da internet. in: LUCCA, Newton De e SIMÃO FILHO, Adalberto (coordenadores) e outros. DIREITO \& INTERNET - aspectos jurídicos relevantes. São Paulo: Quartier Latin, 2ed., 2005. ROCHA, Raquel Heck Mariano da. Modelos de regulamentação: reflexões para um eficiente controle jurídico da publicidade no Brasil. Direito \& Justiça, v. 32, n. 2, p. 200-212, jul./dez. 2012.

SARLET, Ingo Wolfgang. A eficácia dos direitos fundamentais: uma teoria geral dos direitos fundamentais na perspectiva constitucional. 12. ed. Porto Alegre: Livraria do Advogado, 2015.

SCHARF, Edson Roberto. A Proposta de Valor e o Capital Humano: práticas estratégicas de marketing. Revista Brasileira de Gestão de Negócios, v. 14, n. 43, abr./jun., 2012. 